\title{
Comparison of barriers and facilitators of MIND diet uptake among adults from Northern Ireland and Italy
}

Deirdre Timlin, Barbara Giannantoni², Jacqueline M. McCormack ${ }^{3}$, Angela Polito², Donatella Ciarapica², Elena Azzini ${ }^{2}$, Melanie Giles ${ }^{4}$ and Ellen E. A. Simpson ${ }^{*}$

\begin{abstract}
Background: The aim of the study was to identify and compare components of the COM-B (capability, opportunity, motivation and behaviour) model, that influences behaviour to modify dietary patterns in 40-55-year olds living in Northern Ireland (NI) and Italy, in order to reduce the risk of cognitive decline in later life.

Methods: This was a qualitative study examining factors influencing Mediterranean-DASH (Dietary Approaches to Stop Hypertension) Intervention for Neurodegenerative Delay (MIND) diet behaviour. This study further elaborated the COM-B components into the 14 domains of the Theoretical Domains Framework to further understand behaviour. Twenty-five Northern Irish and Italian participants were recruited onto the study, to take part in either a focus group or an interview. Participants were both male and female aged between 40 and 55 years.

Results: Thematic analysis revealed that the main barriers to the uptake of the MIND diet were; time, work environment (opportunity), taste preference and convenience (motivation). Culture (motivation), seasonal foods and lack of family support (opportunity) to be a barrier to the Italian sample only. The main facilitators reported were; improved health, memory, planning and organisation (motivation) and access to good quality food (opportunity). Cooking skills, knowledge (capability) and heathy work lunch (opportunity) reported as a facilitator to the Italian sample only.

Conclusions: Cross-cultural differences in relation to psychosocial barriers and facilitators were found in both samples. More barriers than facilitators towards uptake of the MIND diet were found. There is a need for interventions that increase capability, opportunity, and motivation to aid behaviour change. The findings from this study will be used to design a behaviour change intervention using the subsequent steps from the Behaviour Change Wheel.
\end{abstract}

Keywords: MIND diet, COM-B model, Dementia, Adoption, Brain health, Behaviour change wheel

\section{Background}

The global ageing population is increasing, with approximately 50 million people worldwide currently living with dementia, which is predicted to rise to 131 million by 2050 [1]. The latest statistics on prevalence of dementia

* Correspondence: eea.simpson@ulster.ac.uk

${ }^{4}$ Psychology Research Institute, Ulster University, Coleraine, UK

Full list of author information is available at the end of the article in Europe have shown that overall, Italy has the highest percentage $(2.09 \%)$ of people living with dementia, compared to the average percentage of the rest of Europe (1.55\%). In Northern Ireland, approximately 22,000 people are estimated to be living with dementia, which is $1.06 \%$ of the population. Longevity is increasing worldwide, therefore, there is an urgent need to identify

C C The Author(s). 2021 Open Access This article is licensed under a Creative Commons Attribution 4.0 International License, which permits use, sharing, adaptation, distribution and reproduction in any medium or format, as long as you give appropriate credit to the original author(s) and the source, provide a link to the Creative Commons licence, and indicate if changes were made. The images or other third party material in this article are included in the article's Creative Commons licence, unless indicated otherwise in a credit line to the material. If material is not included in the article's Creative Commons licence and your intended use is not permitted by statutory regulation or exceeds the permitted use, you will need to obtain permission directly from the copyright holder. To view a copy of this licence, visit http://creativecommons.org/licenses/by/4.0/ The Creative Commons Public Domain Dedication waiver (http://creativecommons.org/publicdomain/zero/1.0/) applies to the data made available in this article, unless otherwise stated in a credit line to the data. 
potential modifiable risk factors such as diet to promote brain health from an earlier age.

There have been several prospective and cross-sectional studies that have attempted to gain insight into the relationship between the Mediterranean diet [2], DASH diet [3] and cognitive function. The Mediterranean diet is characterised by a high intake of plant food (fruit, vegetables, cereals and legumes), olive oil as the main source of fat, a moderate intake of fish, a low to moderate intake of dairy products and alcohol, a low intake of saturated fats, meat and poultry [4]. The DASH diet is similar to the Mediterranean diet, however, compared to the Mediterranean diet, the DASH diet requires high intake of low-fat dairy [5]. Prospective studies in the USA and Europe with both the Mediterranean and DASH diets over several years with older adults found an association with less cognitive decline [6,7], specifically, improved episodic, semantic, and working memory [8]. Furthermore, several cross-sectional studies in Italy and NI with older adults, found that close adherence to the Mediterranean diet was associated with lower cognitive impairment $[9,10]$ and better cognitive function [11].

Prospective studies conducted in midlife over an extended 16-year period also showed a significant association with decreased risk of cognitive impairment [12] and improved psychomotor speed over a 4month period in midlife [13]. Research has found that a healthy diet in midlife is positively associated with cognitive function [14]. Moreover, research on both the DASH and Mediterranean diets have shown promising results in the protection against cardio risk factors for dementia [15]. However, the Mediterranean and DASH diets are not specific to the literature on nutrition and the brain. Therefore, a new diet called the Mediterranean-DASH Intervention for Neurodegenerative Delay (MIND) [16] diet was designed that incorporated many of the basic components of Mediterranean and DASH diet, but with modifications that reflect the best scientific evidence on nutrition and prevention of dementia [17].

The MIND diet promotes 10 healthy foods (Leafy greens, other veg, nuts, berries, fish, poultry, olive oil, beans, whole grains, red wine) and limits 5 other foods (red meat, butter, cheese, pastries and sweets, fried foods). While previous research shows that higher consumption of vegetables are associated with lower risk of cognitive decline $[18,19]$, the strongest association is observed for higher intake of leafy greens $[20,21]$. Previous research on cognitive function or dementia do not observe protective effects for overall fruit consumption [20, 21]. However, berries were shown to slow cognitive decline, particularly in global cognition and verbal memory in older adults [22].
There has been limited research to date investigating the effectiveness of the MIND diet. Morris et al. [23] originally devised the MIND diet and found that the diet can slow cognitive decline over an average of 4.7 years in adults aged 58-98 years old [23]. Interestingly, recent research found that the MIND diet and not the Mediterranean diet, protected against 12-year incidence of mild cognitive impairment and dementia in older adults [24]. Also, a large observational study with older adults found that longer adherence to the MIND diet was associated with better verbal memory [25].

While there is little research on the social, environmental, and cultural perspectives of adopting the MIND diet, social and cultural changes have been shown to have contributed to reversal of dietary habits in Southern European countries, with socio-economic variables highlighted as associated with adherence to a Mediterranean diet [26-28]. Social, cultural, and environmental factors have been found to be barriers in adopting a Mediterranean style diet [29, 30]. British culture has been reported as being non-conducive to a Mediterranean dietary pattern [31], with barriers such as time, work and convenience influencing Mediterranean style diet behaviour [32, 33]. Foods from a healthy dietary pattern may be more expensive to buy than those from a less healthy diet [34, 35], and this may influence people's food choices [34]. Therefore, a major barrier to consuming a Mediterranean style diet could be budget, especially for those of low socio-economic status. However, previous research has found, that while consuming healthier foods such as increasing wholegrains, fish, fruit and vegetables, may be more expensive, this cost could be reduced by reducing unhealthier foods such as red meat and sugary foods [36]. Identifying barriers and knowledge gaps towards Mediterranean style diet adoption, such as budget, time, convenience, and work, has implications for the design of behaviour change interventions aiming to promote dietary change [29].

As we are looking to promote healthy ageing, we are investigating modifiable risk factors in the prevention of cognitive decline. Research has found that a healthy diet in midlife is positively associated with cognitive function in later years $[14,15]$. Therefore, this study could add support to the dementia strategy research by exploring modifiable risk factors in the prevention of dementia, which could be applied globally.

\section{Theoretical framework}

The theoretical framework underpinning this research is the COM-B model [37]. Changing behaviour involves changing one or more of the components of the COM-B model, which stand for, capability, opportunity, motivation, and behaviour (see Fig. 1). Capability can be either psychological (knowledge, psychological skills, or 
stamina) to perform the behaviour, or "physical" (having the physical skills, strength or stamina) to perform the behaviour. Opportunity can be divided into "physical" (what the environment allows in terms of time, resources etc) or "social" (interpersonal influences, social cues, cultural norms). Motivation can be divided into "reflective" (self-conscious planning and evaluations, beliefs about what is good or bad) or "automated" (wants and needs, desires, impulse and reflex responses) [37]. The Theoretical Domains Framework (TDF) facilitates understanding of health behaviours around evidencebased guidelines and provides a method to categorise behaviour [38]. Use of the TDF to identify factors influencing MIND diet behaviour can then be mapped onto the COM-B model for designing interventions. The TDF has 14 domains that may influence behaviour change [38] (see Fig. 1).

The COM-B model is at the core of an overarching framework called the Behaviour Change Wheel [37] which is a three-stage approach to designing a behaviour change intervention. This framework includes 9 intervention functions (education, persuasion, incentivisation, coercion, training, restriction, environmental restructuring, modelling, and enablement linked to the COM-B model. These are how an intervention might change behaviour and are linked to behaviour change techniques [37]. BCTs are considered the active component of the intervention designed to change behaviour, such as self-monitoring of behaviour and goal setting. The COM-B model and TDF have been used by several studies to explore barriers and facilitators to behaviour change in sexual health [39], physical activity in obese pregnant women [40] and reducing sugar [41].
Previous research found differences in dietary patterns of people who live in Rome and NI, with NI consuming more ready-made meals [42], snacked between meals more often than Italians [43] and consumed more takeaway food, sugary drinks and less fruits and vegetables that those living in other Mediterranean countries [44]. Although the MIND diet is a hybrid of the Mediterranean and DASH diets, it is a new diet that specifies foods such as berries, leafy greens, and wholegrains, which are not part of a traditional Mediterranean diet. Furthermore, the Mediterranean and DASH diets are not specific to the literature on nutrition and the brain. Therefore, the MIND diet was designed that incorporated many of the basic components of the Mediterranean and DASH diet, but with modifications that reflect the best scientific evidence on nutrition and prevention of dementia [17]. Comparing factors from the COM-B model (capability, opportunity and motivation) that may influence MIND diet behaviour across a Mediterranean and non-Mediterranean country, can reveal valuable insights that highlight diverse habits and beliefs across culture, which may be particularly informative in the development of behaviour change interventions.

The aim of the study was to establish and compare components of the COM-B model that influence the uptake of the MIND diet in a 40-55-year old Italian and Northern Ireland (NI) sample, that will inform a dietary behaviour change intervention.

Specific objectives were:

- To determine participants perceived capability, opportunity, and motivation to the uptake of the MIND diet in 40-55-year olds in a Mediterranean (Italy) and non-Mediterranean (NI) country.

\section{Physical: Skills}

Psychological: Knowledge, behaviour regulation, memory, attention and decision

Physical: Environmental context and resources.

Social: Social influences

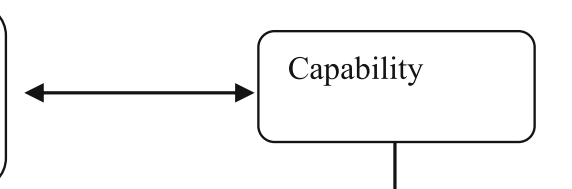

Reflective: Intention, goals, social/professional role and identity, belief about capabilities, belief about consequences, optimism Motivation

Fig. 1 (a): TDF domains and corresponding mapping onto the COM-B component 
- Compare barriers and facilitators to the MIND diet from a Mediterranean and non-Mediterranean country.

- Identify intervention functions and BCTs that are likely to change MIND diet behaviour.

\section{Method}

\section{Participants and study design}

Part of the methods in this manuscript can also be seen in Timlin et al. [45]. Twenty-five participants from NI (Belfast, Armagh city, County Tyrone) (female 60\%, male 40\%) [45] and twenty-five participants from Rome, Italy (female 64\%, male 36\%) aged 40-55 years were recruited onto the study, to take part in either a focus group or an interview. Interview/focus groups took place in person (NI: 15 interviews, 2 focus group $n=6, n=4$; Italy 13 interviews, 2 focus group $n=6 n=6$ ). Ethical approval was obtained from the School of Psychology Staff and Postgraduate Filter Committee at Ulster University, which is in accordance with The Code of Ethics of the World Medical Association (Declaration of Helsinki). Participants were approached by email, Facebook and advertisement booklet, which included some brief information about the study. Interested participants were asked to contact the researcher by email and sent a participant information sheet (PIS), consent form and information booklet on the MIND diet. Questions asked to participants were the same for both NI and Italian populations. Before the Italian interviews began, questions were translated from English to Italian by a fluent Italian speaker (BG). Questions were then back translated to English to ensure the interpretation of questions [46]. Most of the interviews were spoken in English (18) and those that were not were translated during the interviews by one of the Italian researchers (BG), to allow the English-speaking researcher (DT) to transcribe and analyse data from all of the transcripts. All interviews/focus groups were recorded and transcribed verbatim. The oral recordings and transcripts were sent to the Italian speaking researcher to check for missing data. Interviews were conducted in a private room at either a research centre or a community facility such as a library, convenient to the participant. In accordance with the COM-B framework, both focus groups and interviews were conducted [37] using semi-structured questions and lasting between 30 and 60 min each (see Table 1). The interview and focus group questions were based on guidance using the COM-B [37] model and TDF [38] (Table 1). The interview schedule was developed using the COM-B model, and informed the content analyses, as seen in previous research conducted with the NI population of this research, as seen in previous research conducted with the NI population of this research [45]. All participants were asked to complete a personal information form and consent form before the interview/focus group began. The information form contained questions on participants diet at baseline (see Table 2) and showed that those living in NI consumed more red meat, fried food, butter, and sugary foods than those living in Italy. Participants were informed that the study was voluntary and that they could withdraw at any time. They were assured of confidentiality regarding any personal information they supplied to the researcher. It has been suggested by similar theoretical models, that 25 participants is the ideal sample size for qualitative research [47]. Also, similar to other qualitative studies using the COM-B and TDF [39, 40], twenty-five NI and 25 Italian participants were recruited onto the study, to take part in either a focus group or an interview.

\section{Materials and procedure}

A topic guide was developed using the TDF. An example of a question related to TDF knowledge was, "what is your understanding of the MIND diet". A further question exploring participants skills was, "to what extent are you confident in cooking MIND diet foods". The TDF represents an elaboration of the COM-B's six components into 14 domains, covering a wide spectrum of behavioural determinants (see Table 1). A booklet containing information on the elements of the MIND diet, and the origins of the diet were given to participants. An in-depth discussion on the MIND diet components was discussed prior to interview and focus groups. All interviews and focus groups were audio recorded.

\section{Data analyses}

The data analyses has been described in full in Timlin et al. [45]. Two researchers (one English speaking and one Italian/English speaking) (DT\&BG) independently read through the entire dataset and coded the data from each transcript and assigned initial "code names". There was a 95\% agreement on codes between the two main researcher, which demonstrates an acceptable level of agreement [48]. However, any differences in coding were resolved with discussion between the researchers. Summative content analysis [49] was applied as an additional step in the analysis following agreement of codes. This involved two researchers searching the text for occurrences of codes, that were counted to identify the frequency of each code. Using a common approach [50, 51], TDF domains were judged based on the frequency count of coding for each TDF domain, which had been aggregated from all the factors, beliefs or phrases mentioned that fell within that domain. For example, some participants reported that they believed the MIND diet would make them feel better generally. This belief statement is coded under the TDF domain "belief about consequences." The frequency coding identified which TDF 
Table 1 Interview/focus group questions asked to participants in accordance with the TDF and COM-B model

\begin{tabular}{|c|c|c|}
\hline COM-B & TDF & QUESTION \\
\hline $\begin{array}{l}\text { Psychological } \\
\text { Capability }\end{array}$ & Knowledge. & What is your understanding of the MIND diet? \\
\hline $\begin{array}{l}\text { Psychological } \\
\text { Capability }\end{array}$ & $\begin{array}{l}\text { Memory, attention and decision } \\
\text { processes. }\end{array}$ & $\begin{array}{l}\text { To what extent is eating MIND diet foods something you normally do? } \\
>\text { Prompt: Do you eat MIND diet foods each day }\end{array}$ \\
\hline $\begin{array}{l}\text { Psychological } \\
\text { Capability }\end{array}$ & Behaviour regulation & To what extent do you monitor whether you are eating MIND die foods? \\
\hline $\begin{array}{l}\text { Physical } \\
\text { Capability }\end{array}$ & Skills & To what extent are you confident in cooking/eating MIND diet foods? \\
\hline $\begin{array}{l}\text { Social } \\
\text { Opportunity }\end{array}$ & Social influences & $\begin{array}{l}\text { To what extent do/would your family or friends help or hinder you eating MIND diet foods? } \\
>\text { Prompt: Does/would your family support you in eating the MIND diet? }\end{array}$ \\
\hline $\begin{array}{l}\text { Physical } \\
\text { Opportunity }\end{array}$ & $\begin{array}{l}\text { Environmental context and } \\
\text { resources. }\end{array}$ & $\begin{array}{l}\text { Discuss anything in your work or/and home environment that might help or hinder you eating } \\
\text { the MIND diet? E.g budget, time }\end{array}$ \\
\hline $\begin{array}{l}\text { Reflective } \\
\text { Motivation }\end{array}$ & $\begin{array}{l}\text { Social/Professional role and } \\
\text { identity }\end{array}$ & $\begin{array}{l}\text { To what extent would eating the MIND diet be accepted by your friends and family? } \\
>\text { Prompt: Do you think your family/friends influences what you eat? }\end{array}$ \\
\hline $\begin{array}{l}\text { Reflective } \\
\text { Motivation }\end{array}$ & Belief about capabilities & $\begin{array}{l}\text { How difficult/easy would it be for you to eat the MIND diet? } \\
>\text { Prompt: What are the barriers to consuming the MIND diet? } \\
>\text { Prompt: What are the facilitators to consuming the MIND diet? }\end{array}$ \\
\hline $\begin{array}{l}\text { Reflective } \\
\text { Motivation }\end{array}$ & Optimism & $\begin{array}{l}\text { To what extent are you confident that any barriers you may have to eating the MIND diet can } \\
\text { be solved? }\end{array}$ \\
\hline $\begin{array}{l}\text { Reflective } \\
\text { Motivation }\end{array}$ & Intention & To what extent do you intend to follow the MIND diet to promote brain health? \\
\hline $\begin{array}{l}\text { Reflective } \\
\text { Motivation }\end{array}$ & Goals & To what extent would you like to follow the MIND diet? \\
\hline $\begin{array}{l}\text { Reflective } \\
\text { Motivation }\end{array}$ & Belief about consequences & $\begin{array}{l}\text { What do you think will happen if you eat the MIND diet? } \\
>\text { Prompt: Discuss any benefits to eating the MIND diet? }\end{array}$ \\
\hline $\begin{array}{l}\text { Automatic } \\
\text { Motivation }\end{array}$ & Reinforcement & To what extent are there any incentives for you to the MIND diet? \\
\hline $\begin{array}{l}\text { Automatic } \\
\text { Motivation }\end{array}$ & Emotion & How do you feel about eating the MIND diet? \\
\hline
\end{tabular}

COM-B Capability (C): Psychological or physical ability to enact behaviour, Opportunity (O) Physical and social environment that enables behaviour, Motivation (M) Reflective or automatic mechanisms that activate or inhibit behaviour, Behaviour (B), TDF Theoretical Domains Framework [45].

Table 2 Percentage of participants food intake at baseline

\begin{tabular}{|c|c|c|c|c|c|c|c|c|c|c|}
\hline & \multicolumn{2}{|c|}{ More than once a day } & \multicolumn{2}{|l|}{ Daily } & \multicolumn{2}{|c|}{ 2-3 times a week } & \multicolumn{2}{|c|}{ Once a week } & \multicolumn{2}{|c|}{ Less than once a week } \\
\hline & Italy & $\mathrm{NI}$ & Italy & $\mathrm{NI}$ & Italy & $\mathrm{NI}$ & Italy & $\mathrm{NI}$ & Italy & $\mathrm{NI}$ \\
\hline Fruit \& Vegetables \% & 44 & 44 & 26 & 36 & 20 & 20 & 8 & 0 & 4 & 0 \\
\hline Beans and legumes \% & 4 & 0 & 0 & 4 & 44 & 20 & 40 & 24 & 12 & 52 \\
\hline Fish \% & 0 & 0 & 0 & 4 & 32 & 28 & 48 & 40 & 20 & 32 \\
\hline Poultry \% & 0 & 4 & 0 & 4 & 36 & 60 & 36 & 34 & 28 & 8 \\
\hline Wholegrains \% & 12 & 0 & 16 & 40 & 20 & 16 & 16 & 16 & 36 & 28 \\
\hline Nuts \% & 4 & 0 & 16 & 4 & 12 & 20 & 20 & 32 & 40 & 44 \\
\hline Red meat \% & 0 & 0 & 0 & 8 & 28 & 64 & 40 & 12 & 32 & 16 \\
\hline Cheese \% & 0 & 0 & 12 & 24 & 48 & 48 & 24 & 20 & 8 & 8 \\
\hline Fried food $\%$ & 0 & 0 & 0 & 0 & 4 & 40 & 12 & 24 & 84 & 32 \\
\hline Butter \% & 0 & 20 & 0 & 52 & 8 & 12 & 20 & 4 & 72 & 12 \\
\hline Sweets/pastries \% & 0 & 16 & 8 & 28 & 44 & 20 & 8 & 20 & 40 & 12 \\
\hline
\end{tabular}


domains were most commonly reported, establishing the main barriers and facilitators to the uptake of the MIND diet.

\section{Results}

Table 3 reports the characteristics of a total sample, including 25 Italian and 25 NI participants. Transcripts provided data from 12 of the 14 domains of the TDF in the Italian sample, all 14 domains of the TDF in the NI sample and all components of the COM-B model for both samples (see Tables 4 and 5). The most commonly reported barriers and facilitators fell into: Environmental Context and Resources, Belief about Capabilities, Belief about Consequences, Social Influences, Skills and Knowledge. None of the data fell into, reinforcement and goals, which were the least reported domains in the NI study (See Tables 6 and 7 for quotes).

\section{Capability}

Psychological capability was a COM-B component identified as a barrier to adherence to the MIND diet. Twenty percent of the barriers in the Italian sample fell into the psychological component of the COM-B model compared to $29 \%$ in the NI sample. These barriers fell into 2 of the TDF domains, behaviour regulation and knowledge. None of the Italian barriers fell into attention and decision process domain, unlike the NI sample, where $10 \%$ of barriers fell into this domain.

\section{Knowledge}

Similar to the NI sample, all Italian participants reported never having previously heard of the MIND diet. Italian participants reported that they recognised that the MIND diet was similar to the Mediterranean diet and to their own diet.

\section{Behaviour regulation}

This domain is defined as "anything aimed at managing or changing objectively observed or measured actions" [38], such as self-monitoring. In both samples, most of the participants did not monitor their food intake. However, some participants reported that they use to record their food intake to monitor what and how much they ate but are now able to control their diet from memory.

\section{Physical capability: skills}

Physical skills are defined as the level of self-efficacy in cooking/eating with MIND diet foods. Skills were reported as a facilitator in both the NI $(12 \%)$ and Rome samples (8\%). Skills were reported as a key barrier only in the NI sample, with $6 \%$ of barriers falling into this domain. All participants in the Rome sample reported being confident cooks, even if they didn't like or cook certain foods, whereas, in the NI sample, it was reported
Table 3 Summary Characteristics of Interview/Focus Group Participants $(n=50)$

\begin{tabular}{|c|c|c|}
\hline Characteristic & Northern Ireland $(N=25)$ & Italy $(N=25)$ \\
\hline Mean age (sd) & $44(4.9)$ & $46(4.2)$ \\
\hline $40-44$ & $60(15)$ & $36(9)$ \\
\hline $45-49$ & $16(4)$ & $44(11)$ \\
\hline $50-55$ & $24(6)$ & $20(5)$ \\
\hline \multicolumn{3}{|l|}{ Gender } \\
\hline Male & $40(10)$ & $36(9)$ \\
\hline Female & $60(15)$ & $64(16)$ \\
\hline \multicolumn{3}{|l|}{ Occupation } \\
\hline Professional & $44(11)$ & $64(16)$ \\
\hline Skilled & $16(4)$ & $36(9)$ \\
\hline Unskilled & $40(10)$ & 0 \\
\hline \multicolumn{3}{|l|}{ Education } \\
\hline Higher education & $36(9)$ & $64(16)$ \\
\hline Further education & $28(7)$ & $36(9)$ \\
\hline No formal qualifications & $36(9)$ & 0 \\
\hline \multicolumn{3}{|l|}{ Marital status } \\
\hline Married & $44(11)$ & $44(11)$ \\
\hline Co-habiting & $4(2)$ & $4(2)$ \\
\hline Separated & $4(2)$ & $4(2)$ \\
\hline Single & $32(8)$ & $32(8)$ \\
\hline Widowed & $4(2)$ & $4(2)$ \\
\hline \multicolumn{3}{|l|}{ Children in household } \\
\hline Yes & $44(11)$ & $72(18)$ \\
\hline No & $56(14)$ & $28(7)$ \\
\hline
\end{tabular}

Education Level of education obtained within a discipline or profession. Higher education = undergraduate/postgraduate degree: Further education = any study after secondary school that does not include higher education, such as higher national diploma, higher national certificate, apprentices for industry such as hairdressing, plumbing, $S d$ standard deviation $N=50$

that those who couldn't cook generally were married men and those participants who reported that they didn't like certain foods, were not confident in cooking them.

\section{Opportunity}

According to the COM-B model, for behaviour to occur, there must be a physical and social opportunity in the environment. Barriers relating to physical opportunity were the most commonly reported barriers in both the NI and Italian populations, with $29 \%$ of all utterances falling into this component in the NI sample and $33 \%$ in the Italian sample. The TDF domain related to this component is; environmental context and resources. Social opportunity was reported as being a key barrier and facilitator in both the NI and Italian samples, with $13 \%$ of all facilitators and $5 \%$ of barriers falling into this 
Table 4 Barriers in rank order of utterances in relation to MIND diet in 40-55-year olds in Rome and NI: COM-B and TDF domains

\begin{tabular}{|c|c|c|c|c|c|c|c|c|c|}
\hline \multicolumn{5}{|l|}{ Italy } & \multicolumn{5}{|c|}{ Northern Ireland } \\
\hline COM-B & TDF & $\begin{array}{l}\text { Rank } \\
\text { order }\end{array}$ & $\begin{array}{l}\text { Frequency of } \\
\text { Utterances }\end{array}$ & $\begin{array}{l}\% \text { of } \\
\text { utterances. }\end{array}$ & COM-B & TDF & $\begin{array}{l}\text { Rank } \\
\text { order }\end{array}$ & $\begin{array}{l}\text { Frequency of } \\
\text { utterances }\end{array}$ & $\begin{array}{l}\text { \%of } \\
\text { utterances }\end{array}$ \\
\hline $\begin{array}{l}\text { Physical } \\
\text { opportunity }\end{array}$ & $\begin{array}{l}\text { Environmental } \\
\text { context and } \\
\text { resources }\end{array}$ & 1 & 93 & 33 & $\begin{array}{l}\text { Physical } \\
\text { opportunity }\end{array}$ & $\begin{array}{l}\text { Environmental } \\
\text { Context and } \\
\text { resources }\end{array}$ & 1 & 90 & 29 \\
\hline $\begin{array}{l}\text { Social } \\
\text { opportunity }\end{array}$ & Social Influence & 2 & 43 & 15 & $\begin{array}{l}\text { Reflective } \\
\text { motivation }\end{array}$ & $\begin{array}{l}\text { Belief about } \\
\text { capabilities }\end{array}$ & 2 & 46 & 15 \\
\hline $\begin{array}{l}\text { Reflective } \\
\text { motivation }\end{array}$ & $\begin{array}{l}\text { Belief about } \\
\text { Capabilities }\end{array}$ & 3 & 37 & 13 & $\begin{array}{l}\text { Psychological } \\
\text { capability }\end{array}$ & Knowledge & 3 & 37 & 12 \\
\hline $\begin{array}{l}\text { Psychological } \\
\text { capability }\end{array}$ & $\begin{array}{l}\text { Behaviour } \\
\text { regulation }\end{array}$ & 4 & 29 & 10 & $\begin{array}{l}\text { Psychological } \\
\text { capability }\end{array}$ & $\begin{array}{l}\text { Memory, attention, } \\
\text { Decision making }\end{array}$ & 4 & 30 & 10 \\
\hline $\begin{array}{l}\text { Psychological } \\
\text { capability }\end{array}$ & Knowledge & 5 & 29 & 10 & $\begin{array}{l}\text { Psychological } \\
\text { capability }\end{array}$ & $\begin{array}{l}\text { Behaviour } \\
\text { regulation }\end{array}$ & 5 & 24 & 7 \\
\hline $\begin{array}{l}\text { Reflective } \\
\text { motivation }\end{array}$ & $\begin{array}{l}\text { Social, Professional } \\
\text { and Identity }\end{array}$ & 6 & 15 & 5 & $\begin{array}{l}\text { Physical } \\
\text { capability }\end{array}$ & Physical skills & 6 & 17 & 6 \\
\hline $\begin{array}{l}\text { Reflective } \\
\text { motivation }\end{array}$ & $\begin{array}{l}\text { Belief about } \\
\text { consequences }\end{array}$ & 7 & 11 & 4 & $\begin{array}{l}\text { Social } \\
\text { opportunity }\end{array}$ & Social Influence & 7 & 15 & 5 \\
\hline $\begin{array}{l}\text { Physical } \\
\text { capability }\end{array}$ & Skills & 8 & 9 & 3 & $\begin{array}{l}\text { Reflective } \\
\text { motivation }\end{array}$ & $\begin{array}{l}\text { Belief about } \\
\text { consequences }\end{array}$ & 8 & 12 & 4 \\
\hline $\begin{array}{l}\text { Reflective } \\
\text { motivation }\end{array}$ & Intention & 9 & 9 & 3 & $\begin{array}{l}\text { Reflective } \\
\text { motivation }\end{array}$ & $\begin{array}{l}\text { Social professional } \\
\text { and identity }\end{array}$ & 9 & 12 & 4 \\
\hline $\begin{array}{l}\text { Reflective } \\
\text { motivation }\end{array}$ & Optimism & 10 & 7 & 2 & $\begin{array}{l}\text { Reflective } \\
\text { motivation }\end{array}$ & Intention & 10 & 9 & 3 \\
\hline $\begin{array}{l}\text { Automatic } \\
\text { motivation }\end{array}$ & Emotion & 11 & 4 & 2 & $\begin{array}{l}\text { Reflective } \\
\text { motivation }\end{array}$ & Optimism & 11 & 6 & 2 \\
\hline $\begin{array}{l}\text { Automatic } \\
\text { motivation }\end{array}$ & Reinforcement & 0 & 0 & 0 & $\begin{array}{l}\text { Reflective } \\
\text { motivation }\end{array}$ & Goals & 12 & 5 & 2 \\
\hline $\begin{array}{l}\text { Reflective } \\
\text { motivation }\end{array}$ & Goals & 0 & 0 & 0 & $\begin{array}{l}\text { Automatic } \\
\text { motivation }\end{array}$ & Emotion & 13 & 3 & 1 \\
\hline \multirow[t]{2}{*}{$\begin{array}{l}\text { Psychological } \\
\text { capability }\end{array}$} & Memory, attention & 0 & 0 & 0 & $\begin{array}{l}\text { Automatic } \\
\text { motivation }\end{array}$ & Reinforcement & 14 & 1 & 0 \\
\hline & & & 286 & 100 & & & & 307 & 100 \\
\hline
\end{tabular}

Information above the thick black line represents the top 6 reported domains of the TDF and corresponding COM-B components. Eighty percent of the data fell into the top 6 TDF domains, COM-B Capability (C): Psychological or physical ability to enact behaviour, Opportunity (O) Physical and social environment that enables behaviour. Motivation (M): Reflective or automatic mechanisms that activate or inhibit behaviour; Behaviour (B), TDF Theoretical Domains Framework Utterances: Spoken word/words in relation to themes/subthemes emerging from questions asked regarding MIND diet. $n=50$

component from the NI sample, $15 \%$ of all barriers and $12 \%$ of facilitators from the Italian sample. The TDF domain related to this component is social influence.

\section{Environmental context and resources}

This domain is defined as any circumstance of a person's physical environment or situation that could support or hinder the development of skills and abilities [38]. For example, budget, time, inability to cook or shop, availability of quality foods. The work environment was reported as a barrier to eating the MIND diet foods by both NI and Italian samples. It was reported that canteen food can be unhealthy and that there is the temptation to eat more quantity of food. Several participants reported that if they did not have lunch with them, they would eat out in a café or buy lunch from a bakery which would less healthy. Time was a major barrier reported by both samples, particularly for those that were in employment, however, their reasons for time being a barrier differed. For the NI participants, it was more a matter of convenience that they had been working all day, having maybe taken children to after school activities, and did not have the time to cook with fresh foods. The Italian population reported time as barrier in the same manner, but also, the time to travel to access fresh food in the farmers markets in the country, especially for those living in the city.

Budget was also reported as a major barrier to buying several of the MIND diet foods such as fish, berries, and nuts in both populations. However, this was only the view of those participants in low paid jobs or unemployed in the NI sample. Several participants from the Italian sample, who were all professional or skilled 
Table 5 Facilitators in rank order of utterances in relation to MIND diet in 40-55-year olds in Rome and NI: COM-B and TDF domains

\begin{tabular}{|c|c|c|c|c|c|c|c|c|c|}
\hline \multicolumn{5}{|l|}{ Italy } & \multicolumn{5}{|c|}{ Northern Ireland } \\
\hline $\begin{array}{l}\text { FACILITA } \\
\text { TORS } \\
\text { COM-B }\end{array}$ & TDF & $\begin{array}{l}\text { Rank } \\
\text { order }\end{array}$ & $\begin{array}{l}\text { Frequency of } \\
\text { utterances }\end{array}$ & $\begin{array}{l}\text { \% } \\
\text { utterances }\end{array}$ & COM-B & TDF & $\begin{array}{l}\text { Rank } \\
\text { order }\end{array}$ & $\begin{array}{l}\text { Frequency of } \\
\text { utterances }\end{array}$ & $\begin{array}{l}\% \text { of } \\
\text { utterances }\end{array}$ \\
\hline $\begin{array}{l}\text { Physical } \\
\text { opportunity }\end{array}$ & $\begin{array}{l}\text { Environment } \\
\text { context }\end{array}$ & 1 & 48 & 21 & $\begin{array}{l}\text { Reflective } \\
\text { motivation }\end{array}$ & $\begin{array}{l}\text { Belief about } \\
\text { consequences }\end{array}$ & 1 & 28 & 17 \\
\hline $\begin{array}{l}\text { Reflective } \\
\text { motivation }\end{array}$ & $\begin{array}{l}\text { Belief about } \\
\text { Capabilities }\end{array}$ & 2 & 36 & 16 & $\begin{array}{l}\text { Reflective } \\
\text { motivation }\end{array}$ & $\begin{array}{l}\text { Belief about } \\
\text { capabilities }\end{array}$ & 2 & 27 & 16 \\
\hline $\begin{array}{l}\text { Reflective } \\
\text { motivation }\end{array}$ & $\begin{array}{l}\text { Belief about } \\
\text { consequences }\end{array}$ & 3 & 32 & 14 & $\begin{array}{l}\text { Physical } \\
\text { opportunity }\end{array}$ & $\begin{array}{l}\text { Environmental } \\
\text { Context and } \\
\text { resources }\end{array}$ & 3 & 22 & 13 \\
\hline $\begin{array}{l}\text { Social } \\
\text { opportunity }\end{array}$ & Social & 4 & 28 & 12 & $\begin{array}{l}\text { Social } \\
\text { Opportunity }\end{array}$ & Social influence & 4 & 21 & 13 \\
\hline $\begin{array}{l}\text { Physical } \\
\text { capability }\end{array}$ & Skills & 5 & 19 & 8 & $\begin{array}{l}\text { Physical } \\
\text { capability }\end{array}$ & Skills & 5 & 20 & 12 \\
\hline $\begin{array}{l}\text { Reflective } \\
\text { motivation }\end{array}$ & Identity & 6 & 16 & 7 & $\begin{array}{l}\text { Automatic } \\
\text { motivation }\end{array}$ & Emotion & 6 & 15 & 9 \\
\hline $\begin{array}{l}\text { Automatic } \\
\text { motivation }\end{array}$ & Emotion & 7 & 16 & 7 & $\begin{array}{l}\text { Automatic } \\
\text { motivation }\end{array}$ & Reinforcement & 7 & 10 & 6 \\
\hline $\begin{array}{l}\text { Reflective } \\
\text { motivation }\end{array}$ & Optimism & 8 & 10 & 4 & $\begin{array}{l}\text { Reflective } \\
\text { motivation }\end{array}$ & Intention & 8 & 6 & 4 \\
\hline $\begin{array}{l}\text { Reflective } \\
\text { motivation }\end{array}$ & Intention & 9 & 10 & 4 & $\begin{array}{l}\text { Psychological } \\
\text { capability }\end{array}$ & Behaviour regulation & 9 & 4 & 2 \\
\hline $\begin{array}{l}\text { Automatic } \\
\text { motivation }\end{array}$ & Reinforcement & 10 & 7 & 3 & $\begin{array}{l}\text { Reflective } \\
\text { motivation }\end{array}$ & Optimism & 10 & 4 & 2 \\
\hline $\begin{array}{l}\text { Psychological } \\
\text { capability }\end{array}$ & Regulation & 11 & 4 & 2 & $\begin{array}{l}\text { Reflective } \\
\text { motivation }\end{array}$ & $\begin{array}{l}\text { Social/Professional } \\
\text { and identity }\end{array}$ & 11 & 3 & 2 \\
\hline $\begin{array}{l}\text { Psychological } \\
\text { capability }\end{array}$ & Attention & 12 & 3 & 1 & $\begin{array}{l}\text { Psychological } \\
\text { capability }\end{array}$ & Knowledge & 12 & 3 & 2 \\
\hline \multirow[t]{2}{*}{$\begin{array}{l}\text { Psychological } \\
\text { capability }\end{array}$} & Knowledge & 13 & 2 & 1 & $\begin{array}{l}\text { Psychological } \\
\text { capability }\end{array}$ & Memory & 13 & 1 & 1 \\
\hline & & & 231 & 100 & & & & $164^{\prime}$ & 100 \\
\hline
\end{tabular}

Information above the thick black line represents the top 6 reported domains of the TDF and corresponding COM-B components. Eighty percent of the data fell into the top 6 TDF domains; COM-B Capability (C): Psychological or physical ability to enact behaviour, Opportunity (O) Physical and social environment that enables behaviour, Motivation (M) Reflective or automatic mechanisms that activate or inhibit behaviour, Behaviour (B), TDF Theoretical Domains Framework Utterances: Spoken word/words in relation to themes/subthemes emerging from questions asked regarding MIND diet. $n=50$

workers, reported budget to be a barrier, especially with regards to fish and wholegrains.

Treats such as cakes and sweets in the home and workplace were reported as being a major barrier in adhering to the MIND diet in the NI sample. Participants reported that having treats in the house for guests and children would hinder them in adhering to the MIND diet as they often eat the treats themselves. Also, NI participants reported that treats in the workplace were common, that there were always biscuits available and that this would be a hindrance to adhering to the MIND diet. However, treats in the workplace were not reported by the Italian sample, in fact, when asked if biscuits were commonly found in the workplace, participants reported that it was only on occasion that biscuits or treats were offered at work, such as, someone's birthday.
A major barrier reported by the Italian sample and a key difference between both samples, was access and availability of certain foods of the MIND diet. Most Italian participants reported that the availability of berries out of season were scarce. One participant reported that, Italy provides so many different, tasty fruit, that they would not choose berries that were hard to find and expensive. Several participants also reported that wholegrains were expensive and hard to find. Italian participants also reported that access to fresh fruit, vegetables and fish may hinder them in adhering to the MIND diet, especially those that lived in the city of Rome. Participants reported that the fish and fruit produce in the city is more expensive and poorer quality than in the country and that they would consume less of these because of this reason. In contrast, the NI sample reported that the fruit and vegetables were more 
Table 6 Quotes from barriers regarding uptake of the MIND diet in rank order

\begin{tabular}{|c|c|c|c|c|c|}
\hline \multicolumn{3}{|c|}{ Northern Ireland } & \multicolumn{3}{|l|}{ Rome } \\
\hline COM-B/TDF & SUB-THEME & QUOTE & COM-B/TDF & Subtheme & QUOTE \\
\hline $\begin{array}{l}\text { Physical } \\
\text { opportunity: } \\
\text { Environmental } \\
\text { context }\end{array}$ & $\begin{array}{l}\text { 1. Time } \\
\text { 2. Food } \\
\text { environment } \\
\text { at work/ } \\
\text { canteen } \\
\text { 3. Budget } \\
\text { 4. Treats in for } \\
\text { kids. }\end{array}$ & $\begin{array}{l}\text { "For me it is time, by the time you get } \\
\text { home from work, and maybe have done } \\
\text { overtime, you couldn't be bothered" } \\
\text { "There is nothing healthy in a canteen" }\end{array}$ & $\begin{array}{l}\text { Physical } \\
\text { opportunity: } \\
\text { Environmental } \\
\text { context }\end{array}$ & $\begin{array}{l}\text { 1. } \\
\text { Availability/ } \\
\text { Access to } \\
\text { food } \\
\text { 2. Budget } \\
\text { 3. Time } \\
\text { 4. Season }\end{array}$ & $\begin{array}{l}\text { "Finding berries and the cost of them are } \\
\text { a barrier" } \\
\text { "Berries are hard to find as they are } \\
\text { seasonal, I only eat them in summer" }\end{array}$ \\
\hline $\begin{array}{l}\text { Reflective } \\
\text { motivation: } \\
\text { Belief about } \\
\text { capabilities }\end{array}$ & $\begin{array}{l}\text { 1. } \\
\text { Convenience } \\
\text { 2. Taste } \\
\text { preference } \\
\text { 3. Mindset }\end{array}$ & $\begin{array}{l}\text { "Kids don't want healthy stuff, so } \\
\text { sometimes I have convenience stuff to } \\
\text { make it easier for me" } \\
\text { "I don't like fish, you know the strong } \\
\text { smelling fishy fish" }\end{array}$ & $\begin{array}{l}\text { Social } \\
\text { opportunity: } \\
\text { Social } \\
\text { influence }\end{array}$ & $\begin{array}{l}\text { 1. Family } \\
\text { influence } \\
\text { 2. Visiting } \\
\text { family } \\
\text { And friends }\end{array}$ & $\begin{array}{l}\text { "The problem is my family, they only eat } \\
\text { white pasta" } \\
\text { "I would cook more unhealthily and } \\
\text { quantity if family are visiting" }\end{array}$ \\
\hline $\begin{array}{l}\text { Psychological } \\
\text { capability: } \\
\text { Knowledge }\end{array}$ & $\begin{array}{l}\text { 1. Lack } \\
\text { knowledge of } \\
\text { MIND diet } \\
\text { and foods }\end{array}$ & $\begin{array}{l}\text { "If you don't know what is healthy for } \\
\text { your brain, you won't eat that way" }\end{array}$ & $\begin{array}{l}\text { Reflective } \\
\text { motivation: } \\
\text { Belief about } \\
\text { capabilities }\end{array}$ & $\begin{array}{l}\text { 1. Taste } \\
\text { preference } \\
2 . \\
\text { Convivence } \\
\text { Mindset }\end{array}$ & $\begin{array}{l}\text { I don't buy the brown pasta as it is more } \\
\text { expensive and it doesn't taste as nice as } \\
\text { the white" } \\
\text { "I don't eat vegetables, any kind of them" } \\
\text { "I love cheese, I do not think I could eat } \\
\text { less cheese" }\end{array}$ \\
\hline $\begin{array}{l}\text { Psychological } \\
\text { capability: } \\
\text { Memory, } \\
\text { attention and } \\
\text { decision } \\
\text { process }\end{array}$ & $\begin{array}{l}\text { 1. Alcohol } \\
\text { 2. Tired } \\
\text { 3. Holidays }\end{array}$ & $\begin{array}{l}\text { "If I had a good drink at the weekend, it } \\
\text { would take Tuesday or Wednesday to get } \\
\text { over it, and I wouldn't want to eat this } \\
\text { food" }\end{array}$ & $\begin{array}{l}\text { Psychological } \\
\text { capability: } \\
\text { Behaviour } \\
\text { regulation }\end{array}$ & $\begin{array}{l}\text { 1. Self- } \\
\text { monitoring }\end{array}$ & "No, I don't monitor my food intake" \\
\hline $\begin{array}{l}\text { Psychological } \\
\text { capability: } \\
\text { Behaviour } \\
\text { regulation }\end{array}$ & $\begin{array}{l}\text { 1. Lack } \\
\text { monitoring of } \\
\text { food } \\
\text { consumption }\end{array}$ & $\begin{array}{l}\text { "No, I don't, and sure, when I go to } \\
\text { weight watchers, I don't even do it" }\end{array}$ & $\begin{array}{l}\text { Psychological } \\
\text { capability: } \\
\text { Knowledge }\end{array}$ & $\begin{array}{l}\text { 1. Lack } \\
\text { knowledge } \\
\text { of MIND } \\
\text { diet. }\end{array}$ & "I have never heard of the MIND diet" \\
\hline $\begin{array}{l}\text { Physical } \\
\text { capability: } \\
\text { Skills }\end{array}$ & $\begin{array}{l}\text { 1. Lack } \\
\text { cooking skills }\end{array}$ & $\begin{array}{l}\text { "I couldn't cook that, if you handed me all } \\
\text { the ingredients, I would be like, what am I } \\
\text { doing with it" }\end{array}$ & $\begin{array}{l}\text { Social, } \\
\text { professional } \\
\text { and identity. }\end{array}$ & 1. Culture & $\begin{array}{l}\text { "My family eat lots of food, lots of white } \\
\text { pasta and cheese, this is typical of } \\
\text { Southern Italians to eat more and are } \\
\text { more overweight" } \\
\text { "Berries are not part of our culture" }\end{array}$ \\
\hline
\end{tabular}

COM-B Capability, Opportunity, Motivation, Behaviour, TDF Theoretical domains framework

expensive and of poorer quality in the country and small towns, and that they would have to travel to the bigger stores to access cheaper better-quality food.

Both samples reported that bringing their lunch to work, would help facilitate adherence to the MIND diet. Participants reported, that in order to consume the MIND diet at work, they would need to bring their own lunch to prevent them from eating out. Many participants from the Italian sample already brought a healthy lunch to work, such as salad, which they perceived would help prevent barriers in adhering to the MIND diet, as they could take a lunch to work containing MIND diet foods.

\section{Social influence}

This domain is described as the "interpersonal processes that can cause individual to change their thoughts, feelings or behaviours, which may be due to social pressure, norms, social/family support or peer pressure" [38]. A key barrier reported by both samples was visiting family/ friends. Both samples reported that either going out to visit friends or family coming to visit resulted in eating unhealthier and more quantity. However, the NI sample reported eating more fast foods, while the Italian sample reported cooking more unhealthily, such as lasagne, cheese and pasties and more quantity. Family support/ influence was reported as a key facilitator by both samples. Participants from NI sample reported that they felt their family would support them if they were to uptake the MIND diet. Another key barrier under this domain which was only reported by the Italian sample, was lack of family support/influence. Participants often reported avoiding certain foods such as wholegrains or eating less healthy foods such as vegetables, as other family members did not like them. Also, several participants reported that their family would not support them in this diet, particularly those who originate from the South of Italy, where eating more food and more unhealthily is typical of their culture.

\section{Motivation}

Motivation is a component of the COM-B model and there must be strong motivation for the behaviour to 
Table 7 Quotes from participants regarding facilitators of uptake of the MIND diet

\begin{tabular}{|c|c|c|c|c|c|}
\hline \multicolumn{3}{|l|}{ Northern Ireland } & \multicolumn{3}{|l|}{ Rome } \\
\hline COM-B/TDF & SUBTHEME & QUOTE & COM-B/TDF & SUBTHEME & QUOTE \\
\hline $\begin{array}{l}\text { Reflective } \\
\text { motivation: } \\
\text { Belief about } \\
\text { consequences }\end{array}$ & $\begin{array}{l}\text { 1. Feel better } \\
\text { generally } \\
\text { 2. Improve } \\
\text { psychological } \\
\text { health } \\
\text { 3. Improve } \\
\text { memory }\end{array}$ & $\begin{array}{l}\text { "I think the diet would just help } \\
\text { you feel better generally" } \\
\text { "And even help your head, less } \\
\text { stress and worry" }\end{array}$ & $\begin{array}{l}\text { Physical } \\
\text { Opportunity: } \\
\text { Environmental } \\
\text { context and } \\
\text { Resources }\end{array}$ & $\begin{array}{l}\text { 1. Bring } \\
\text { lunch } \\
\text { 2. Time }\end{array}$ & $\begin{array}{l}\text { "Here I bring lunch every day, it is very } \\
\text { simple for me to prepare my salads so not } \\
\text { a barrier" } \\
\text { "Having the time to travel to get better } \\
\text { quality food would be a facilitator". }\end{array}$ \\
\hline $\begin{array}{l}\text { Reflective } \\
\text { motivation: } \\
\text { Belief about } \\
\text { capabilities }\end{array}$ & $\begin{array}{l}\text { 1. Planning/ } \\
\text { preparation/ } \\
\text { organisation }\end{array}$ & $\begin{array}{l}\text { "Organisation and preparation the } \\
\text { night before, so having your } \\
\text { berries and salad ready for work" }\end{array}$ & $\begin{array}{l}\text { Reflective } \\
\text { motivation: } \\
\text { Belief about } \\
\text { capabilities }\end{array}$ & $\begin{array}{l}\text { 1. Normal } \\
\text { diet } \\
\text { 2. Simple } \\
\text { meals } \\
\text { 3. } \\
\text { Organisation } \\
\text { 4. } \\
\text { Motivation }\end{array}$ & $\begin{array}{l}\text { "sometimes it is easier for all the family if } \\
\text { you can cook it quickly, like pasta and } \\
\text { veg" } \\
\text { "If you were motivated enough, I think } \\
\text { you could overcome your barriers". } \\
\text { "I think you need to plan and be } \\
\text { motivated". }\end{array}$ \\
\hline $\begin{array}{l}\text { Physical } \\
\text { opportunity: } \\
\text { Environmental } \\
\text { context and } \\
\text { resources }\end{array}$ & $\begin{array}{l}\text { 1. Accessibility } \\
\text { fresh/frozen } \\
\text { food } \\
\text { 2. Bring lunch } \\
\text { to work }\end{array}$ & $\begin{array}{l}\text { "I would go to Lidl, because it is } \\
\text { cheaper and better quality" } \\
\text { "In my work, you need to be } \\
\text { prepared and bring lunch with } \\
\text { you" }\end{array}$ & $\begin{array}{l}\text { Reflective } \\
\text { motivation: } \\
\text { Belief about } \\
\text { consequences }\end{array}$ & $\begin{array}{l}\text { 1. Overall } \\
\text { health } \\
\text { 2. } \\
\text { Cholesterol } \\
\text { 3. Lose } \\
\text { weight } \\
\text { 4. Fiber/ } \\
\text { bowel }\end{array}$ & $\begin{array}{l}\text { "I think this diet could help you gain more } \\
\text { health" } \\
\text { "I think my bowels would work better on } \\
\text { this diet" } \\
\text { "I think with eating less cheese would be } \\
\text { good for your cholesterol" } \\
\text { "I think you could lose weight on this } \\
\text { diet" }\end{array}$ \\
\hline $\begin{array}{l}\text { Social } \\
\text { opportunity: } \\
\text { Social influence }\end{array}$ & $\begin{array}{l}\text { 1. Family } \\
\text { support/ } \\
\text { influence }\end{array}$ & $\begin{array}{l}\text { "My mum is always cutting out } \\
\text { articles showing me research on } \\
\text { good and bad foods for your } \\
\text { health. }\end{array}$ & $\begin{array}{l}\text { Social opportunity: } \\
\text { Social influence }\end{array}$ & $\begin{array}{l}\text { 1. Family } \\
\text { support/ } \\
\text { influence }\end{array}$ & $\begin{array}{l}\text { "Yes, my wife would support me if I } \\
\text { wanted to do this diet" } \\
\text { "yes, I think if I was out with family, there } \\
\text { would be more alcohol, unhealthy foods } \\
\text { and less veg" }\end{array}$ \\
\hline $\begin{array}{l}\text { Physical } \\
\text { capability: Skills }\end{array}$ & $\begin{array}{l}\text { 1. Confident } \\
\text { cook }\end{array}$ & $\begin{array}{l}\text { "I am pretty confident cooking } \\
\text { these foods" }\end{array}$ & $\begin{array}{l}\text { Physical capability: } \\
\text { Skills }\end{array}$ & $\begin{array}{l}\text { 1. Confident } \\
\text { cook }\end{array}$ & $\begin{array}{l}\text { "Yes, I cook generally the same legumes, I } \\
\text { don't like beans very much so I don't cook } \\
\text { them often, but I am able to cook them" }\end{array}$ \\
\hline \multirow[t]{2}{*}{$\begin{array}{l}\text { Automatic } \\
\text { motivation: } \\
\text { Emotion }\end{array}$} & 1. Positive & $\begin{array}{l}\text { "I would be positive about it, I get } \\
\text { excited trying new things" }\end{array}$ & $\begin{array}{l}\text { Reflective } \\
\text { motivation } \\
\text { Professional, social } \\
\text { and identity }\end{array}$ & 1. Culture & $\begin{array}{l}\text { "this is typical foods for me, this would } \\
\text { not be difficult for me" } \\
\text { "we don't eat butter, it is not in our } \\
\text { culture, we use olive oil" }\end{array}$ \\
\hline & & & $\begin{array}{l}\text { Automatic } \\
\text { motivation } \\
\text { Emotion }\end{array}$ & 1. Positive & $\begin{array}{l}\text { "I would feel positive about doing this } \\
\text { diet" }\end{array}$ \\
\hline
\end{tabular}

COM-B Capability, Opportunity, Motivation, Behaviour, TDF Theoretical domains framework

occur [33]. Participants reported reflective motivation to be a barrier to the uptake of the MIND diet and $18 \%$ of barriers fell into this component of the COM-B model, compared to $15 \%$ in the NI study. More facilitators were reported under this domain with $33 \%$ from the NI sample and $37 \%$ from the Rome sample.

\section{Belief about capabilities}

The extent to which the individual believes they were able to adhere to the MIND diet. Taste preference was reported as a major barrier to the adherence of the MIND diet in both the NI and Italian populations. Participants reported not liking various elements of the diet such as fish, vegetables, and chicken. However, many of the participants in the Italian sample reported not liking wholegrains, in particular, wholegrain pasta or bread and even if they did like it, they would not buy it as their children did not eat it. Convenience was also reported as a barrier to the uptake of the MIND diet in both samples. Both samples reported cooking less healthy food to suit their children and eating it themselves rather than making two meals for convenience.

Mindset was reported by both samples as a barrier to the uptake of the MIND diet. The NI sample reported that being in the right mindset was important to change diet and to be determined to do so. However, the Italian sample reported the difficulty they perceived in reducing certain foods, such as cheese. Many Italian participants reported that they would not be able to do this. Belief about capabilities were also reported as being a major facilitator in the uptake of the MIND diet with $16 \%$ of all barriers falling into this domain in both samples. While both samples reported that being organised and 
prepared when cooking meals or having lunch prepared for work was a facilitator, the Italian participants reported that the MIND diet seemed similar to their own diet and would be easy to follow. They also reported that the MIND diet allowed for simple meals such as pasta and vegetables which is quick and easy to make.

\section{Professional, social and identity}

How the individual viewed the uptake/maintenance of the MIND diet relative to their identity (for example, parent, culture). Culture was reported as both a barrier (3\%) and a facilitator (7\%) under this domain from the Italian sample only. Participants reported that the MIND diet was similar to their own diet and the Mediterranean diet. Participants reported that as they ate most of these foods, that this would help them adhere to the MIND diet. They also reported that butter is not part of their diet, they only use olive oil which further supports uptake of the MIND diet. However, most participants reported that not only were berries hard to find out of season, but they were not part of their culture. Some participants also reported that wholegrains were not part of their culture and it would not be acceptable to serve wholegrains to family and friends. It was also reported that cheese is a big part of the Italian culture and reducing cheese would be difficult to do.

\section{Belief about consequences}

This domain is described as, anticipated outcomes of not eating brain healthy foods, anticipated or experienced outcomes of eating brain healthy foods. (positive or negative). Belief about consequences was reported as a major facilitator in both samples with it being the most reported facilitator in the NI sample (17\%). Both samples reported that if they adhered to the MIND diet, they believed it would be good for their overall health, less sleepy and improve mental health. However, some of the Italian participants recognised that with more fibre from the wholegrains and less cheese, that this would have a benefit for their bowels and cholesterol.

\section{Emotion}

Both samples reported that they would feel positive about following the MIND diet with 7\% of facilitators falling into this domain in the Italian sample and $9 \%$ in the NI sample. However, similar to NI participants, even though participants felt positive about the MIND diet, this did not necessarily coincide with their intention to uptake the diet.

\section{Discussion}

To our knowledge, this is the first study investigating adherence to the MIND diet at midlife (40-55 years old) in a Mediterranean and non-Mediterranean country. This study addresses this gap in the literature and highlights cross-cultural perceived barriers and facilitators to adhering to the MIND diet at midlife. Results found that the main barriers and facilitators reported were; environmental context and resources, belief about capabilities, social influence, behaviour regulation, knowledge, skills, belief about consequences, emotion, memory, attention and decision making, and professional, social identity, which can be mapped onto the COM-B model (see Fig. 1). This is the first study to use the COM-B model to code and analyse cross-cultural qualitative responses from individuals at midlife regarding MIND diet behaviour. The reason for this, was to ensure our findings were grounded in theory and identify the main components of an intervention that could change and maintain behaviour.

Similar to the NI sample, the Italian key barriers reported were: environmental context and resources, belief about capabilities, behaviour regulation and knowledge. However, skills, and memory, attention and decision processes were not reported as key barriers in the Rome population. Instead, social influence and social, professional and identity were reported as key barriers to the uptake of the MIND diet. Key facilitators reported were environmental context and resources, belief about capabilities, belief about consequences, social influences, skills, and emotion. The Italian sample reported one further facilitator which was social, professional and identity. Our results confirmed previous research finding regarding commonly reported barriers and facilitators to adherence to healthy dietary change, including budget [52], time and taste preference [53] and family influence [54].

Similar to the NI population, the Italian sample reported having no knowledge of the MIND diet prior to the study or what constituted brain healthy food. Nicklas et al. [55] found that lack of knowledge regarding dietary recommendations and health benefits were reported as a key barrier in meeting dietary recommendations, and lack of information on healthy food was also reported as a major barrier [56].

Lack of monitoring food intake was reported by both samples, highlighting "capability" as major barrier to the uptake of the MIND diet. Previous research found an association between behaviour regulation and changes in dietary outcomes [57], with self-monitoring specifically associated with a positive change in diet $[58,59]$. Selfmonitoring is shown to not only increase awareness of eating patterns $[60,61]$, but also allows professionals to identify food aversions/intolerances and poor food choices [61].

Opportunity was highlighted as a key barrier to the uptake of the MIND diet. The main difference between the two samples was due to social influences being 
reported as a barrier in the Italian sample but not the NI sample. Environmental context and resource was a major theme to emerge with "Time" being a key factor in both samples, mainly reported by those who led busy lives. This finding supports previous research that found "Time" to be a barrier to eating a healthy diet $[62,63]$. Busy lifestyle was found to be associated with less home cooked meals [56] and poorer eating habits [64-66].

"Budget" was also found to be a significant barrier in both samples, which was mainly due to the healthy elements of the MIND diet, such as fish, wholegrains, berries, and nuts. These findings support previous research that found the cost of food to be a significant factor in people's choice of food and consumption [34], and that higher adherence to a whole dietary pattern such as the Mediterranean diet, had higher cost associated with the healthy elements of the diet (fish, fruit, vegetables, nuts), and lower cost to the unhealthy elements of the diet (processed meat and sweet) [56, 67]. These findings are further supported in Roa et al. [35] that found unhealthy processed foods to be less expensive than fruit, vegetables, and nuts. However, Roa et al. [35] explained that the higher cost could be offset by reducing the amount of unhealthy food consumption. Further support for this was found in Germani et al. [68] who compared the cost of a 4-member family with the cost of the same family following the Mediterranean diet and found that the cost of the Mediterranean diet was slightly higher in the overall budget. However, following an increase in the budget for healthy foods such as fruit and vegetables and reducing the budget for unhealthy foods such as pastries and processed food, the overall cost for both diets were similar. It was therefore concluded that low adherence to the Mediterranean diet was not associated with cost but a difference in allocating money to different food groups.

Access and availability of fresh food was reported as both a barrier and facilitator in both samples. However, the Italian sample reported it as a major barrier compared to the NI sample and for different reasons, mainly due to seasonal foods being unavailable and limited access to fresh foods reported by those living in the city. One interesting difference between the two samples under this barrier is that in NI, there is cheaper, better quality food in the bigger stores and cities. However, it was reported that it is in the country markets in Rome that cheaper, fresher food is found. The literature generally supports that access to fresh cheaper foods are a barrier in rural areas. Previous research found that shops selling healthier food was a long distance from country communities [69, 70], and that limited access to food resources led to poorer dietary habits [71].

However, in line with our findings with the Italian sample, previous research found that those who had access to farmers markets or grew their own food, was a facilitator to healthy eating [72]. However, the Italian sample further reported that farmers markets only open in the morning which did not suit those who worked. This finding is supported in Smith et al. [73], that found farmers markets to have inconvenient times and low frequency. Barnridge et al. [74] found that participants reported eating the recommended daily fruit and vegetables when receiving nutrition education and access to a garden. However, those who received no nutrition education but access to the garden, did not report eating the recommended fruit and vegetable, suggesting that it is knowledge not access to the garden that was related to an increase in fruit and vegetable consumption.

Social influence was reported as a barrier to the uptake of the MIND diet by the Italian sample only, and as a facilitator by both samples. Family influence was reported as key barrier in the Italian sample. This may be due to the Italian sample being influenced by their children with $72 \%$ of the sample having children in the home compared to only $44 \%$ of the NI sample. The Italian sample often reported that their children would not eat certain elements of the MIND diet such as wholegrains or vegetables, influencing their decision to buy or cook such foods. This finding is supported in the literature that the taste preference of family and friends is a barrier to healthy eating [56]. Furthermore, research found the preference of children and family to be an important barrier when adopting a healthier lifestyle, particularly with increasing consumption of healthy foods. However, family support and influence were also reported as a key facilitator in adhering to the MIND diet, which is consistent with previous research that found family support was associated with healthier foods [75, 76].

Motivation was highlighted as a barrier and facilitator to the uptake of the MIND diet in both samples. A major barrier reported in both samples was belief about capabilities, with taste preference being a factor associated with adhering to the MIND diet. This finding is in line with previous research that found taste preference to be a barrier to healthy eating [56]. Morrow et al. [77] found that men were more likely to eat healthily if they did not perceive taste to be a barrier. Many of the Italian participants reported that the MIND diet was very similar to their own diet and therefore, felt it would be quite easy to follow. Previous research found that level of education is associated with healthy eating [78-80] and the Italian sample are all educated with $76 \%$ of the Italian sample with a higher qualification compared to $36 \%$ of the NI sample with a higher qualification and $36 \%$ with no formal qualifications. Research found that level of nutritional knowledge is associated with length of education and awareness of food related issues, leading individuals to be more interested in a balanced dietary 
pattern [27, 28]. However, the Italian sample perception of the MIND diet adherence ease may be attributable to their culture. The MIND diet is a Mediterranean style diet and many of the Italian participants reported following their cultural diet which is rich in fruit, vegetables, nuts, grains, and olive oil, and that this in itself is a facilitator to adhering to the MIND diet. Research in the Mediterranean countries have found that the Mediterranean diet is progressively disappearing $[4,81]$. However, research estimating adherence to the Mediterranean diet in the Mediterranean countries using secondary data, found that Italy had the best adherence to the Mediterranean diet [82]. Even though Italians had the best adherence to the Mediterranean diet, it was still decreasing since the economic crisis [83].

Culture was also reported as a barrier to adhering to the MIND diet in the Italian sample only. Participants often reported that certain MIND diet foods were not typical of their culture and serving certain foods to family and friends were not acceptable, such as wholegrain pasta and bread. This finding is in support of previous research that found low consumption of wholegrains in a Spanish sample [84, 85]. Baruth et al. [86], found family to be a barrier to healthy eating. It was reported in Baruth's study that pressure to eat more, and the expectation that women would not lose their curves, were barriers to healthy eating. Furthermore, the sample in Baruth's study was with African American women, and as food is a big part of socialising, and eating traditional food is an important to their cultural identity, African American women may feel pressure to eat more [86].

The findings from this study are important to understand behaviour in the context in which it occurs. These findings not only highlight the components of the COM-B/TDF that need to change in order change behaviour, but the cultural differences in terms of important factors that need addressed in intervention design. The development of an appropriate intervention depends on the understanding of MIND diet behaviour in context, and the findings from this study provides us with the necessary knowledge of factors influencing behaviour that will inform an intervention. This is important, as an intervention to change MIND diet behaviour in Northern Ireland, may not address the needs of those living in Italy. The COM-B model is at the core of an overarching framework called the Behaviour Change Wheel [37] which is a 3-stage systematic approach to designing a behaviour change intervention. The research in this paper represents stage one, to understand behaviour in the context in which it occurs and identify what needs to change in order to change MIND diet behaviour.

Stage 2 identifies the best intervention functions that are most likely to be effective in changing the target behaviour in context. We found that 5 of the 9 intervention functions suggested by the $\mathrm{BCW}$ were most relevant to the COM-B behavioural analysis conducted in this study. The 5 intervention functions were: education (increasing knowledge), training (imparting skills), persuasion (influencing attitudes and actions), enablement (providing support to overcome barriers) and environmental restructure (to provide cues and prompts for desired behaviour) [37].

The third stage helps identify content of the intervention by selecting the most appropriate behaviour change techniques which best serve the intervention function. The Behaviour Change Technique Taxonomy v1(BCTTv1) [87], and the theory and techniques tool [88], identified which BCT's have direct links to the TDF domains being addressed in the MIND diet intervention. For example, the tool showed that there was a link between TDF behaviour regulation and self-monitoring of behaviour. Fifteen BCT's were identified as likely to be effective in delivering the intervention functions and bringing about change in MIND diet behaviour. Therefore, capability to promote adoption of the MIND diet will be addressed by offering demonstration and instruction on how to perform the behaviour, such as recipes, information on MIND diet food frequency and portion sizes. Opportunity to promote adoption of the MIND diet will be addressed by adding objects to the environment, prompts/cues, remove aversive stimuli such as removing unhealthy snacks, bringing lunch to work and social support. Motivation to promote adoption of the MIND diet will be addressed by a range of selfregulatory $\mathrm{BCT}$ s such as goal setting, problem solving, self-monitoring, action planning and information on health consequences. In particular, self-monitoring resources to enable individuals to track their MIND diet behaviour and setting particular goals to meet the weekly MIND diet guidelines.

\section{Strengths}

To our knowledge, this is the first study to develop a "behavioural diagnosis" of factors influencing the uptake of the MIND diet in a Mediterranean and nonMediterranean country. This was the first study to apply the TDF to explore people's attitudes towards a whole dietary pattern and compare these attitudes between a Mediterranean and non-Mediterranean country. The COM-B model provides a more comprehensive explanation of adherence than existing models [37], making it easier to identify appropriate interventions. The COM-B model was used as an additional step in the data analysis, increasing the efficiency of the study and showing the framework to be adequate for its purpose. 


\section{Limitations}

This study was undertaken in a small sample of Italian and Northern Irish men and women. Our findings in terms of barriers and facilitators reported are "perceived" and context based. Therefore, not only may the findings have limited value in predicting MIND diet behaviour, but also not be generalisable to the whole populations. However, generalisability was not the main aim of our study, rather to explore people's attitudes and perceptions towards the uptake and adherence to the MIND diet, with the aim to inform an intervention. Another limitation of the study may be researcher subjectivity; however, two researchers identified the codes from the data, suggesting that the themes drawn have credence beyond the lead researcher's interpretation. Focus groups run the risk of introducing bias [89], resulting from an individual's desire to conform to social acceptability [90]. However, the focus group participants in this study were acquaintances, reducing the risk of social desirability. A limitation of this study is that the two samples differ in terms of socio-economic status, with all the participants from the Italian sample being of high socioeconomic status and approximately one-third of the NI participants of low socio-economic status, which may make comparisons more difficult. Further research should include participants across different socioeconomic backgrounds. Furthermore, half of the Italian participants spoke in Italian and some of the richness of the data may have been lost in translation. However, the second researcher (Italian) translated, transcribed, and analysed the data to maximise interpretation and understanding of the data.

\section{Conclusion}

The COM-B and TDF makes a novel application to understanding what would influence the uptake of the MIND diet. This research identified that the main barriers to the uptake of the MIND diet were; time, work environment (opportunity), taste preference and convenience (motivation), with culture (motivation), seasonal foods and lack of family support (opportunity) to be a barrier to the Italian sample only. The main facilitators reported were; improved health, memory, planning and organisation (motivation) and access to good quality food (opportunity). Cooking skills, knowledge (capability) and heathy work lunch (opportunity) being a facilitator to the Italian sample only. Developing interventions that target these salient barriers to MIND diet uptake will have greater potential to change behaviour. Following detailed behavioural analysis, we used the subsequent stages of the Behaviour Change Wheel to identify 5 intervention functions and 15 BCTs to address the barriers and facilitators to the uptake of the MIND diet.
The findings from this study recommends providing behaviour regulation techniques, such as self-monitoring of MIND diet behaviour to keep track of adherence to MIND diet recommendations, education to increase knowledge of MIND diet and its components, improve skills by providing recipes and weekly food planner, and advice on how to include family in the promotion of MIND diet behaviour. Further strategies to overcome barriers to MIND diet behaviour are to provide advice on planning meals ahead of time to encourage adherence to the MIND diet, provide information on how to overcome workplace diet traps, such as bringing lunch to work and removing unhealthy snacks from workdesk. Future research can use the insight from this paper to test the effectiveness of the intervention functions and BCTs outlined in these findings. Furthermore, understanding barriers and facilitators towards uptake of the MIND diet may help health professionals working with individuals/communities to help prevent or reduce the risk of cognitive decline.

\section{Abbreviations \\ AD: Alzheimer's Disease; BCW: Behaviour Change Wheel; COM-B: Capability, Opportunity, Motivation and Behaviour; DASH diet: Dietary Approaches to Stop Hypertension; HAPA: Health Action Process Approach; HBM: Health Belief Model; Med diet: Mediterranean Diet; MIND diet: Mediterranean-DASH Intervention for Neurodegenerative Delay; NI: Northern Ireland; PIS: Participant Information Sheet; SCT: Social Cognitive Theory; SDT: Self- Determination Theory; TCS: Theory Coding Scheme; TDF: Theoretical Domains Framework; TTM: Transtheoretical Model; TPB: Theory of Planned Behaviour; UK: United Kingdom; USA: United States of America}

\section{Acknowledgments}

The authors would like to thank all the participants who took part in the study and also to the businesses that allowed access to their customers.

Availability of data and material

The dataset (individual transcripts) is not publicly available due to confidentiality and ethical reasons.

\section{Funding sources}

This research is part of a PhD thesis funded by The Department for the Economy (DfE), the funding body for PhD research in Northern Ireland. The funding body had no role in the research.

\section{Authors' contributions}

DT/BG led the study and conducted all the interviews/focus groups. DT/BG also analysed, coded and interpreted the data. DT wrote the manuscript. ES was also closely involved with data analyses and coding of the data. ES, JMCC, AP, MG, EA, DC revised the manuscript critically for intellectual content. All authors read and approved the final manuscript.

\section{Ethics approval}

Ethical approval was obtained from the School of Psychology Staff \& Postgraduate Filter Committee, Ulster University, which is in accordance with The Code of Ethics of the World Medical Association (Declaration of Helsinki).

\section{Consent for publication}

All participants provided written informed consent before participating in the study, which included consent to publish anonymous quotes from individual participants. 


\section{Author details}

${ }^{1}$ School of Psychology, Ulster University, Ulster, UK. ${ }^{2}$ CREA - Council for Agricultural Research and Economics Research Centre for Food and Nutrition, Via Ardeatina, 546, 00178 Rome, Italy. ${ }^{3}$ Faculty of Science, Institute of Technology, Sligo, Ireland. ${ }^{4}$ Psychology Research Institute, Ulster University, Coleraine, UK

Received: 10 June 2020 Accepted: 21 January 2021

Published online: 02 February 2021

\section{References}

1. World Health Organization. Global action plan on the public health response to dementia 2017-2025. 2017.

2. Panagiotakos DB, Pitsavos C, Stefanadis C, Arvanti F. Adherence to the Mediterranean food pattern predicts the prevalence of hypertension, Hyperholesterolemia, diabetes and obesity, among healthy adults; the accuracy of the MedDietScore. Prev Med. 2007;44(4):335-40.

3. Sacks FM, Appel LJ, Moore TJ, et al. A dietary approach to prevent hypertension: a review of the dietary approaches to stop hypertension (DASH) study. Clin Cardiol. 1999;22(S3):6-10.

4. Burlingame B, Dernini S. Sustainable diets: the Mediterranean diet as an example. Public Health Nutr. 2011;14:2285-7.

5. Berendsen AA, Kang JH, van de Rest O, Feskens EJ, de Groot LC, Grodstein F. The dietary approaches to stop hypertension diet, cognitive function, and cognitive decline in American older women. J Am Med Directors Assoc. 2017:18(5):427-32.

6. Galbete $\mathrm{C}$, Toledo E, Toledo JB, et al. Mediterranean diet and cognitive function: the SUN project. J Nutr Health Aging. 2015;19(3):305-12.

7. Trichopoulou A, Kyrozis A, Rossi M, et al. Mediterranean diet and cognitive decline over time in an elderly Mediterranean population. Euro J Nutri. 2015;54(8):1311-21.

8. Tangney CC, Li H, Wang Y, et al. Relation of DASH- and Mediterranean-like dietary patterns to cognitive decline in older persons. Neurol. 2014;83(16): 1410-6.

9. De Amicis $\mathrm{R}$, Leone $\mathrm{A}$, Foppiani $\mathrm{A}$, et al. Mediterranean diet and cognitive status in free-living elderly: a cross-sectional study in northern Italy. J Am Coll Nutr. 2018;37(6):494-500.

10. Tierney A, Zabetakis I. Changing the Irish dietary guidelines to incorporate the principles of the Mediterranean diet: proposing the MedÉire diet. Public Health Nutr. 2019;22(2):375-81.

11. McEvoy CT, Moore SE, Cupples ME, et al. Development of a peer support intervention to encourage dietary behaviour change towards a Mediterranean diet in adults at high cardiovascular risk. BMC Public Health 2018;18(1):1194

12. Bhushan A. Mediterranean diet adherence is associated with reduced subjective cognitive decline in a healthy adult population (doctoral dissertation). 2019

13. Smith PJ, Blumenthal JA, Baby AK, et al. Effects of the dietary approaches to stop hypertension diet, exercise, and caloric restriction on Neurocognition in overweight adults with high blood pressure. Hypertens. 2010;55(6):1331-8.

14. Samieri C, Sun Q, Townsend MK, et al. The association between dietary patterns at midlife and health in aging. An observational study. Ann Intern Med. 2013;159(9):584-91

15. Kesse-Guyot E, Andreeva VA, Jeandel C, Ferry M, Hercberg GP. A healthy dietary pattern at midlife is associated with subsequent cognitive performance. J Nutr. 2012;142(5):909-15.

16. Morris MC, Tangney CC, Wang Y, Barnes LL, Bennett D, Aggarwal N. Mind diet score more predictive than Dash or Mediterranean diet scores. Alzheimers Dement. 2014;10(4):166.

17. Morris, M. C. Diet for the Mind: The Latest Science on What to Eat to Prevent Alzheimer's and Cognitive Decline. (2018). Macmillan.

18. Chen X, Huang Y, Cheng HG. Lower intake of vegetables and legumes associated with cognitive decline among illiterate elderly Chinese: a 3-year cohort study. J Nutri Health Aging. 2012;16(6):549-52.

19. Nooyens AC, Bueno-de-Mesquita HB, van Boxtel MP, et al. Fruit and vegetable intake and cognitive decline in middle-aged men and women: the Doetinchem cohort study. Br J Nutri. 2011;106(5):752-61.

20. Morris MC, Wang $Y$, Barnes $L L$, et al. Nutrients and bioactives in green leafy vegetables and cognitive decline: prospective study. Neurol. 2018;90(3): e214-22.
21. Morris MC, Evans DA, Tangney CC, et al. Associations of vegetable and fruit consumption with age-related cognitive change. Neurol. 2006;67(8):1370-6.

22. Devore EE, Kang JH, Breteler MM, et al. Dietary intakes of berries and flavonoids in relation to cognitive decline. Ann Neurol. 2012;72(1):135-43.

23. Morris MC, Wang Y, Tangney CC, Sacks FM, Bennett DA, Aggarwal NT. MIND diet associated with reduced incidence of Alzheimer's disease. Alzheimers Dement. 2015;11(9):1007-14.

24. Hosking DE, Eramudugolla R, Cherbuin N, et al. MIND not Mediterranean diet related to 12-year incidence of cognitive impairment in an Australian longitudinal cohort study. Alzheimers Dement. 2019.

25. Berendsen AM, Feskens EJM, CPGM d G, van der Kang JH, Grodstein F. Association of long-term adherence to the mind diet with cognitive function and cognitive decline in American women. J Nutr Health Aging. 2018;22(2):222-9.

26. Lopez CN, Martinez-Gonzalez MA, Sanchez-Villegas A, Aloso A, Pimenta AM, Bes-Rastrollo M. Costs of Mediterranean and western dietary patterns in a Spanish cohort and their relationship with prospective weight change. J Epidemiol Community Health. 2009;63(11):920-7.

27. Bonaccio M, Bonanni $A E$, Di Castelnuovo $A$, et al. Low income is associated with poor adherence to a Mediterranean diet and a higher prevalence of obesity: cross-sectional results from the Moli-sani study. BMJ Open. 2012; 2(6):e001685.

28. Bonaccio M, Di Castelnuovo A, Costanzo S, et al. Nutrition knowledge is associated with higher adherence to Mediterranean diet and lower prevalence of obesity. Results from the Moli-sani study. Appetite. 2012;68: 139-46.

29. Moore SE, McEvoy CT, Prior L, Lawton J, Patterson CC, Kee F, Cupples M, Young IS, Appleton K, McKinley MC, Woodside JV. Barriers to adopting a Mediterranean diet in northern European adults at high risk of developing cardiovascular disease. J Hum Nutr Diet. 2018;31(4):451-62.

30. Haigh L, Bremner S, Houghton D, Henderson E, Avery L, Hardy T, Hallsworth K, McPherson S, Anstee Q. Effective dietary interventions for non-alcoholic fatty liver disease: barriers and facilitators to adoption of a Mediterranean diet in a northern European patient population. Hepatol. 2017;1(66):S420.

31. Middleton G, Smith MF, Keegan R, et al. Implementing a Mediterranean diet intervention into a RCT: lessons learned from a non-Mediterranean based country. J Nutr Health Aging. 2015;19(10):1019-22.

32. Pinho MG, Mackenbach JD, Charreire H, Oppert JM, Bárdos H, Glonti K, Rutter H, Compernolle S, De Bourdeaudhuij I, Beulens JW, Brug J. Exploring the relationship between perceived barriers to healthy eating and dietary behaviours in European adults. Eur J Nutr. 2018;57(5):1761-70.

33. Nicholls R, Perry L, Duffield C, Gallagher R, Pierce H. Barriers and facilitators to healthy eating for nurses in the workplace: an integrative review. J Adv Nurs. 2017;73(5):1051-65.

34. Kearney M, Kearney JM, Dunne A, Gibney MJ. Sociodemographic determinants of perceived influences on food choice in a nationally representative sample of Irish adults. Public Health Nutr. 2000;3(2):219-26.

35. Rao M, Afshin A, Singh G, Mozaffarian D. Do healthier foods and diet patterns cost more than less healthy options? A systematic review and meta-analysis. BMJ Open. 2013:3:12

36. Kretowicz $H$, Hundley V, Tsofliou F. Exploring the perceived barriers to following a Mediterranean style diet in childbearing age: a qualitative study. Nutrients. 2018;10(11):1694.

37. Michie S, Atkins L, West R. The behaviour change wheel. A guide to designing interventions. Great Britain: Silverback Publishing; 2014. p. 1003-10.

38. Cane J, O'Conner D, Michie S. Validation of the theoretical domains framework for use in behaviour change and implementation research. Implement Sci. 2012;7:37.

39. Cassidy C, Bishop A, Steenback A, Langille D, Martin-Misener R, Curran J. Barriers and enablers to sexual health service use among university students: a qualitative descriptive study using the theoretical domains framework and COM-B model. BMC Health Serv Res. 2018:18(1):581.

40. Bentley MR, Mitchell N, Sutton L, Backhouse SH. Sports nutritionists' perspectives on enablers and barriers to nutritional adherence in high performance sport: A qualitative analysis informed by the COM-B model and theoretical domains framework. J Sports Sci. 2019;25:1-1.

41. Al Rawahi SHA, Asimakopoulou K, Newton JT. Factors related to reducing free sugar intake among white ethnic adults in the UK: a qualitative study. BDJ Open. 2018;4:17024-4. 
42. Simpson EEA, O'Connor JM, Livingstone MBE, Rae G, Stewart-Knox BJ, Andriollo-Sanchez M, et al. Health and lifestyle characteristics of older European adults: the ZENITH study. Eur J Clin Nutr. 2005;59(2):S13-21.

43. Huseinovic E, Winkvist A, Slimani N, Park MK, Freisling $H$, Boeing $H$, et al. Meal patterns across ten European countries-results from the European Prospective Investigation into Cancer and Nutrition (EPIC) calibration study. Public Health Nutr. 2016;19(15):2769-80.

44. Fitzpatrick I, MacMillan T, Hawkes C, Anderson A, Dowler E. Understanding food culture in Scotland and its comparison in an international context: implications for policy development. Edinburgh: NHS Scotland; 2010.

45. Timlin D, McCormack JM, Simpson L. Using the COM-B model to identify barriers and facilitators towards adoption of a diet associated with cognitive function (MIND diet): barriers and facilitators to the MIND diet. Public Health Nutr. 2020:1-14.

46. Brislin RW. Back-translation for cross-cultural research. J Cross-Cult Psychol. 1970;1(3):185-216.

47. Francis JJ, Johnston M, Robertson C, Glidewell L, Entwistle V, Eccles MP, Grimshaw JM. What is an adequate sample size? Operationalising data saturation for theory-based interview studies. Psychol Health. 2010;25(10):1229-45.

48. Hartmann DP. Considerations in the choice of interobserver reliability estimates. J Appl Behav Anal. 1977;10(1):103-16.

49. Hsieh HF, Shannon SE. Three approaches to qualitative content analysis. Qual Health Res. 15(9):1277-88.

50. Bussieres AE, Patey AM, Francis JJ, Sales AE, Grimshaw JM. Canada PRIme plus team, identifying factors likely to influence compliance with diagnostic imaging guideline recommendations for spine disorders among chiropractors in North America: a focus group study using the theoretical domains framework. Implement Sci. 2012;7:82-91.

51. Lake AJ, Browne JL, Rees G, Speight J. What factors influence uptake of retinal screening among young adults with type 2 diabetes? A qualitative study informed by the theoretical domains framework. J Diabetes Complicat. 2017;31(6):997-1006.

52. Petroka K, Dychtwald DK, Milliron B, Campbell-Bussiere R. Barriers and facilitators to healthy eating and disease self-management among older adults residing in subsidized housing. Nutr Health. 2017;23(3):167-75.

53. De Mestral C, Sreinghini S, Marques Vidal P. Barriers to healthy eating in Switzerland: a nationwide study. Clin Nutr. 2016;35(6):1490-8.

54. Pinho MGM, Mackenbach JD, Charreire $\mathrm{H}$, et al. Exploring the relationship between perceived barriers to healthy eating and dietary Behaviours in European adults. Eur J Nutr. 2018;57(5):1761-70.

55. Nicklas TA, Lopez S, Liu Y, et al. Barriers and facilitators for consumer adherence to the dietary guidelines for Americans: the HEALTH study. J Acad Nutr Diet. 2013;113(10):1317-31.

56. Ashton LM, Hutchesson MJ, Rollo ME, Morgan PJ, Collins CE. Motivators and barriers to engaging in healthy eating and physical activity: a cross-sectional survey in Young adult men. Am J Mens Health. 2017;11(2):330-43.

57. Greaves CJ, Sheppard KE, Abraham C, et al. Systematic Review of Reviews of Intervention Components Associated with Increased Effectiveness in Dietary and Physical Activity Interventions. BMC Public Health. 2011;11:119.

58. Lynch Al, Reznar MM, Zalesin KC, Bohn D. To keep myself on track: the impact of dietary and weight monitoring behaviors on weight loss after bariatric surgery. Bariatric Surg Pract Pat Care. 2018;13(1):44-52.

59. Teasdale $N$, Elhussein $A$, Butcher $F$, et al. Systematic review and metaanalysis of remotely delivered interventions using self-monitoring or tailored feedback to change dietary behavior. Am J Clin Nutr. 2018; 107(2):247-56

60. Chung LM, Law QP, Fong SS, Chung JW. Electronic dietary recording system improves nutrition knowledge, eating attitudes and habitual physical activity: a randomised controlled trial. Eat Behav. 2014;15(3):410-3.

61. McGrice M, Paul KD. Interventions to improve long-term weight loss in patients following bariatric surgery: challenges and solutions. Diab Metab Syndr Obes. 2015;8:263.

62. Hibbs-Shipp S, Milholland M, Bellows L. Barriers and facilitators to healthy eating and activity in head start staff: an opportunity for worksite wellness. Am J Health Educ. 2015;46(6):347-50.

63. Nicholls R, Perry L, Pierce H, Duffield C, Gallagher R. Barriers and facilitators to healthy eating for nurses in the workplace: an integrative review. J Adv Nurs. 2017;73(5):1051-65.

64. Fernandes J, Portela L, Rotenberg L, Griep R. Working hours and health behaviour among nurses at public hospitals. Rev Lat Am Enfermagem. 2013. 21(5):1104-11.
65. Nahm E, Warren J, Zhu S, An M, Brown J. Nurses' self-care behaviors related to weight and stress. Nurs Outlook. 2012;60(5):e23-31.

66. Phiri LP, Draper CE, Lambert EV, Kolbe-Alexander TL. Nurses' lifestyle behaviours, health priorities and barriers to living a healthy lifestyle: a qualitative descriptive study. BMC Nurs. 2014;13(1):38.

67. Tong TYN, Imamura F, Monsivais $P$, et al. Dietary cost associated with adherence to the Mediterranean diet, and its variation by socio-economic factors in the UK fenland study. Br J Nutr. 2018;119(6):685-94.

68. Germani A, Vitiello V, Giusti AM, Pinto A, Donini LM, del Balzo V. Environmental and economic sustainability of the Mediterranean diet. Int J Food Sci Nutr. 2014;65(8):1008-12.

69. Maley M, Warren BS, Devine CM. Perceptions of the environment for eating and exercise in a rural community. J Nutr Educ Behav. 2010;42(3):185-91.

70. Neill C, Leipert BD, Garcia AC, Kloseck M. Using Photovoice methodology to investigate facilitators and barriers to food acquisition and preparation by rural older women. J Nutr Gerontol Geriatr. 2011;30(3):225-47.

71. Carnahan LR, Zimmermann K, Peacock NR. What rural women want the public health community to know about access to healthful food: a qualitative study, 2011. Prev Chronic Dis. 2016;13:E57.

72. Seguin R, Connor L, Nelson M, Lacroix A, Eldridge G. Understanding barriers and facilitators to healthy eating and active living in rural communities. Journal of Nutrition and Metabolism. 2014.

73. Smith $\mathrm{C}$, Miller H. Accessing the food systems in urban and rural Minnesotan communities. J Nutr Educ Behav. 2011;43(6):492-504.

74. Barnidge EK, Baker EA, Schootman M, Motton F, Sawicki M, Rose F. The effect of education plus access on perceived fruit and vegetable consumption in a rural African American community intervention. Health Educ Res. 2015;30(5):773-85.

75. Pawlak R. Colby. Benefits, barriers, self-efficacy and knowledge regarding healthy foods; perception of African Americans living in eastern North Carolina. Nutr Res Pract. 2009;3(1):56-63.

76. Walker SN, Pullen CH, Hertzog M, Boeckner L, Hageman PA. Determinants of Older Rural Women's Activity and Eating...Including Commentary by Wilbur J, Zenk SN with Response by Walker, Pullen, Boeckner, and Hageman. West J Nurs Res. 2006;28(4):449-68.

77. Mc Morrow L, Ludbrook A, Macdiarmid JI, Olajide D. Perceived barriers towards healthy eating and their association with fruit and vegetable consumption. J Public Health. 2017;39(2):330-8.

78. Chandola T, Clarke P, Morris JN, Blane D. Pathways between education and health: a causal modelling approach. J R Stat Soc Ser A Stat Soc. 2006; 169(2):337-59.

79. Cutler DM, Lleras-Muney A. Education and health: evaluating theories and evidence. Natl Bur Econ Res. No. w12352. 2006.

80. Thornton LE, Pearce JR, Ball K. Sociodemographic factors associated with healthy eating and food security in socio-economically disadvantaged groups in the UK and Victoria, Australia. Public Health Nutr. 2014;17(1):20-30.

81. Dernini S, Berry EM, Serra-Majem L, et al. Med diet 4.0: the Mediterranean diet with four sustainable benefits. Public Health Nutr. 2017;20(7):1322-30.

82. Finardi C, Bucchini L, Turrini A. "Mediterranean diet 'reflections'". Estimating adherence to the Mediterranean diet through secondary data. Prog Nutr. 2018;2(3):344-60.

83. Benedetti I, Biggeri L, Lauretti T, Secondi L. Exploring the Italians' food habits and tendency towards a sustainable diet: the Mediterranean eating pattern. Agricult Agricult Sci Proced. 2016:8:433-40.

84. Bautista-Castaño I, Sánchez-Villegas A, Estruch R, Martínez-González MA, Corella D, Salas-Salvadó J, Lamuela-Raventós RM. Changes in bread consumption and 4-year changes in adiposity in Spanish subjects at high cardiovascular risk. Br J Nutr. 2013;110(2):337-46.

85. Ruiz-Cabello P, Fernández MM, Gallo FJ, et al. Adherence to the Mediterranean diet in a group of midlife women: the FLAMENCO project. Rev Andal Med Deport. 2015;8(1):42.

86. Baruth M, Sharpe PA, Wilcox S, Parra-medina D. Perceived barriers to exercise and healthy eating among women from disadvantaged neighborhoods: results from a focus groups assessment. Women Health. 2014;54(4):336-53.

87. Michie S, Richardson M, Johnston M, Abraham C, Francis J, Hardeman W, et al. The behavior change technique taxonomy (v1) of 93 hierarchically clustered techniques: building an international consensus for the reporting of behavior change interventions. Ann Behav Med. 2013:46:81-95.

88. Connell LE, Carey RN, de Bruin M, Rothman AJ, Johnston M, Kelly MP, Michie S. Links between behavior change techniques and mechanisms of action: an expert consensus study. Ann Behav Med. 2019;53(8):708-20. 
89. Harrison M, Milner-Gulland E, Baker J, Twinamatsiko M. Profiling unauthorized natural resource users for better targeting of conservation interventions. Conserv Biol. 2015;29(6):1636-46.

90. Acocella I. The focus groups in social research: advantages and disadvantages. Qual Quant. 2012;46(4):1125-36.

\section{Publisher's Note}

Springer Nature remains neutral with regard to jurisdictional claims in published maps and institutional affiliations.

Ready to submit your research? Choose BMC and benefit from:

- fast, convenient online submission

- thorough peer review by experienced researchers in your field

- rapid publication on acceptance

- support for research data, including large and complex data types

- gold Open Access which fosters wider collaboration and increased citations

- maximum visibility for your research: over $100 \mathrm{M}$ website views per year

At BMC, research is always in progress.

Learn more biomedcentral.com/submissions 